\title{
Polycythemia Vera Diagnosed after Esophageal Variceal Rupture
}

\author{
Yoshiyasu Kono ${ }^{1}$, Akinobu Takaki ${ }^{1}$, Hideo Gobara ${ }^{2}$, Ken-ichi Matsuoka ${ }^{3}$, \\ Masato Nishino ${ }^{4}$, Hiroyuki Okada ${ }^{5}$ and Kazuhide Yamamoto ${ }^{1}$
}

\begin{abstract}
Polycythemia vera (PV) is a chronic myeloproliferative neoplasm that leads to hyperviscosity and the risk of thrombosis. We encountered the case of a young male Filipino patient diagnosed with PV after the rupture of esophageal varices. The complete blood cell count showed a slight increase in white blood cells. An abdominal computed tomography scan disclosed splenomegaly and occlusion of the portal vein and collateral vessels. A blood examination demonstrated an increase in all three blood cell lines within three months. Based on the presence of severe hypercellularity of the bone marrow and positivity for the JAK2V617F mutation, we finally diagnosed the patient with PV.
\end{abstract}

Key words: polycythemia vera (PV), esophagogastric varices, thrombosis, portal hypertension

(Intern Med 54: 2395-2399, 2015)

(DOI: 10.2169/internalmedicine.54.4687)

\section{Introduction}

Polycythemia vera (PV) is a chronic myeloproliferative disorder characterized by an increased red blood cell mass (RCM) or erythrocytosis, which leads to hyperviscosity and an increased risk of thrombosis. PV should be suspected in patients exhibiting elevated hemoglobin or hematocrit levels, splenomegaly and/or portal venous thrombosis, which may be causes of esophagogastric varices (1). Portal venous thrombosis associated with splenomegaly may reduce the blood cell count, thus masking polycythemia. Recently, the $J A K 2 V 617 F$ mutation has been reported to be present in the majority of patients with PV, and JAK2V617 screening is useful for identifying patients with latent PV in whom the complete blood count (CBC) appears to be relatively normal (2). We herein present the case of a male Filipino patient diagnosed as $\mathrm{PV}$ after the rupture of esophageal varices. He exhibited a normal blood cell count, except for a relatively high white blood cell level, which masked the signs of PV.

\section{Case Report}

The patient was a 28-year-old male Filipino patient who had complained of epigastric discomfort lasting for one year. He had been urgently transported to a previous hospital because of hematemesis in July. Urgent esophagogastroduodenoscopy (EGD) was performed, and gushing bleeding with esophageal varices of Lm, F2 was seen. Therefore, endoscopic variceal ligation (EVL) was carried out, and the red color (RC) sign (red wale marking) was found almost completely circumferentially in the lower esophagus (Fig. 1A, B). After additional treatment with endoscopic injection sclerotherapy (EIS), he was referred to our hospital for further treatment and examinations in September of the same year.

The patient had no past medical, family or drinking history. Table shows the blood examination results obtained on the initial visit to our hospital. The white blood cell count was $12,570 / \mu \mathrm{L}$, the red blood cell count was $564 \times 10^{4} / \mu \mathrm{L}$ and the platelet cell count was $328 \times 10^{3} / \mu \mathrm{L}$, showing an in-

\footnotetext{
${ }^{1}$ Department of Gastroenterology and Hepatology, Okayama University Graduate School of Medicine, Dentistry and Pharmaceutical Sciences, Japan, ${ }^{2}$ Department of Radiology, Okayama University Hospital, Japan, ${ }^{3}$ Department of Hematology and Oncology, Okayama University Hospital, Japan, ${ }^{4}$ Department of Internal Medicine, Okayama Kyouritsu Hospital, Japan and ${ }^{5}$ Department of Endoscopy, Okayama University Hospital, Japan

Received for publication December 9, 2014; Accepted for publication March 24, 2015

Correspondence to Dr. Akinobu Takaki, akitaka@md.okayama-u.ac.jp
} 


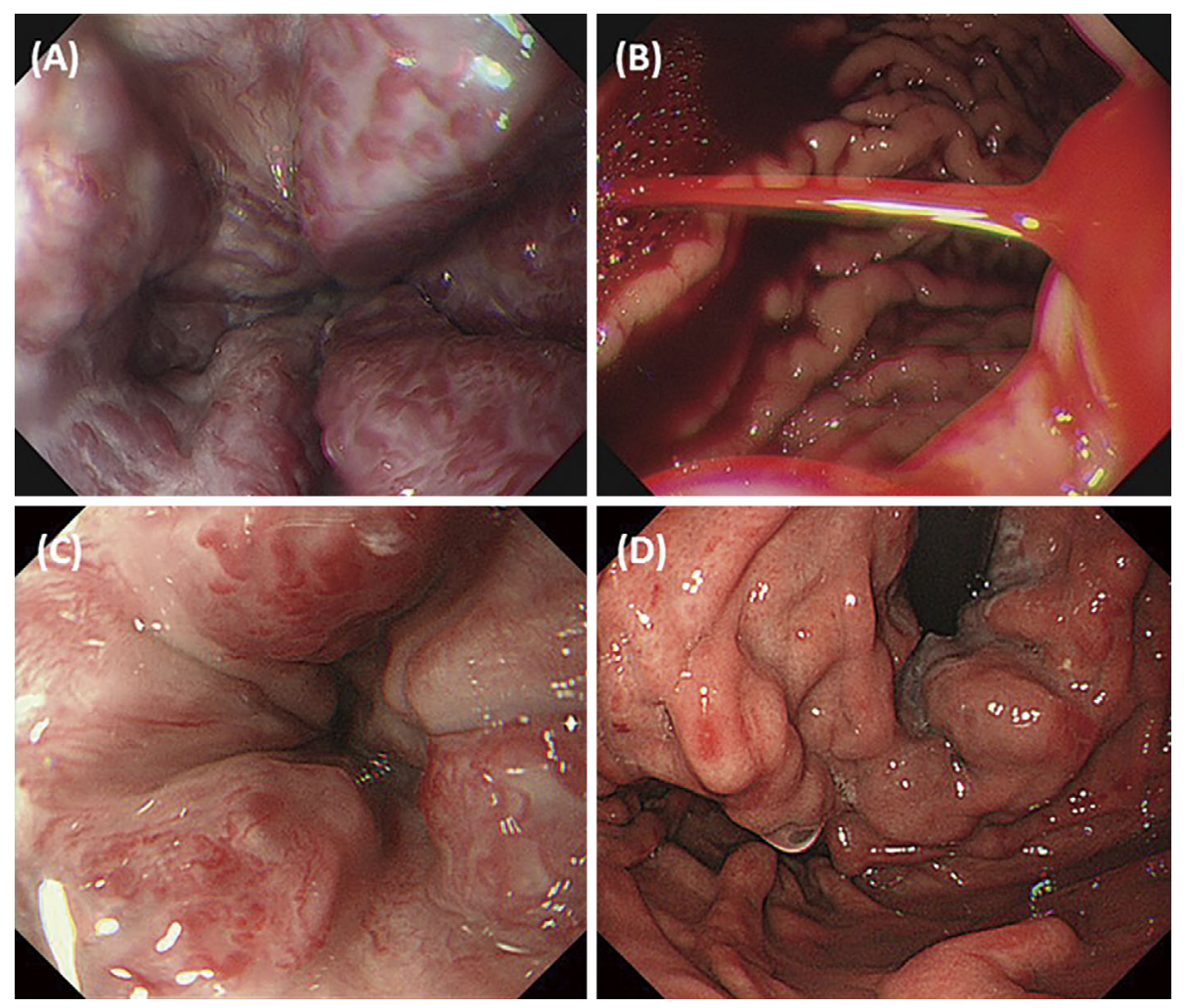

Figure 1. Endoscopic images of emergency esophagogastroduodenoscopy $(\mathrm{A}, \mathrm{B})$ and those obtained on the initial visit to our hospital (C, D). (A) Esophageal varices of F2 were seen. Red wale markings were found almost completely circumferentially in the lower esophagus. (B) Gushing bleeding was detected. (C) Esophageal varices of $\mathrm{F} 2$ and red color (RC) signs remained in the lower esophagus. (D) Gastric varices of $\mathrm{F} 2$ were observed in the cardia; however, there were no $\mathrm{RC}$ signs.

Table. Laboratory Data.

\begin{tabular}{lrlrlr}
\hline Hematology & \multicolumn{4}{c}{ Blood chemistry } & Coagulation \\
\hline WBC & $12,570 / \mu \mathrm{L}$ & AST & $41 \mathrm{U} / \mathrm{L}$ & PT & $67 \%$ \\
Sg+St & $73 \%$ & ALT & $39 \mathrm{U} / \mathrm{L}$ & APTT & $48.4 \mathrm{~s}$ \\
Ly & $5.0 \%$ & ALP & $385 \mathrm{U} / \mathrm{L}$ & Fib & $201 \mathrm{mg} / \mathrm{dL}$ \\
Mon & $6.0 \%$ & $\gamma-\mathrm{GT}$ & $66 \mathrm{U} / \mathrm{L}$ & & \\
Eos & $4.0 \%$ & LDH & $317 \mathrm{U} / \mathrm{L}$ & Serology & \\
Bas & $2.0 \%$ & CK & $46 \mathrm{U} / \mathrm{L}$ & $\mathrm{HBs}-\mathrm{Ag}$ & $(-)$ \\
$\mathrm{RBC}$ & $564 \times 14^{4} / \mu \mathrm{L}$ & $\mathrm{TP}$ & $8.0 \mathrm{~g} / \mathrm{dL}$ & $\mathrm{HBs}-\mathrm{Ab}$ & $(-)$ \\
$\mathrm{Hb}$ & $12.7 \mathrm{~g} / \mathrm{dL}$ & Alb & $4.6 \mathrm{~g} / \mathrm{dL}$ & $\mathrm{HBe}-\mathrm{Ag}$ & $(-)$ \\
$\mathrm{Hct}$ & $40.3 \%$ & $\mathrm{~T}-\mathrm{Bil}$ & $0.81 \mathrm{mg} / \mathrm{dL}$ & $\mathrm{HBe}-\mathrm{Ab}$ & $(-)$ \\
$\mathrm{MCV}$ & $71.4 \%$ & $\mathrm{Na}$ & $139 \mathrm{mEq} / \mathrm{L}$ & $\mathrm{HBc}-\mathrm{Ab}$ & $(-)$ \\
$\mathrm{MCH}$ & $22.5 \%$ & $\mathrm{~K}$ & $4.4 \mathrm{mEq} / \mathrm{L}$ & $\mathrm{HCV}-\mathrm{Ab}$ & $(-)$ \\
$\mathrm{MCHC}$ & $31.5 \%$ & $\mathrm{Cl}$ & $105 \mathrm{mEq} / \mathrm{L}$ & & \\
$\mathrm{PLT}$ & $328 \times 10^{3} / \mu \mathrm{L}$ & $\mathrm{BUN}$ & $8.8 \mathrm{mg} / \mathrm{dL}$ & & \\
& & $\mathrm{Cr}$ & $0.71 \mathrm{mg} / \mathrm{dL}$ & & \\
& & AMY & $106 \mathrm{U} / \mathrm{L}$ & \\
\end{tabular}

crease in only one blood cell line. He had slightly elevated hepatic and biliary enzyme levels, although there were no signs of hepatitis $\mathrm{B}$ or $\mathrm{C}$ viral infection. EGD was reassessed in our hospital (Fig. 1C, D), which showed esophageal varices of Lm, F2 and the RC sign, despite the previous treatment with EIS. An abdominal computed tomography (CT) scan revealed massive splenomegaly as well as occlusion of the portal vein and marked hepatopetal collateral vessels (Fig. 2A, B). We also performed angiography. The image of the superior mesenteric arteriography showed cav- ernous transformation around the occluded portal vein (Fig. 2C), while the image of celiac arteriography showed that the main trunk of the splenic artery was occluded and that the branches were tortuous. There was also a collateral blood circulation from the dorsal pancreatic artery and left gastric artery (Fig. 2D). Additionally, we confirmed based on the patient's stool specimen that he was not infected with any parasites. After a consultation with a hematologist, chronic myeloid leukemia was ruled, out as bcr/abl amplification was not detected. Unfortunately, a further bone mar- 

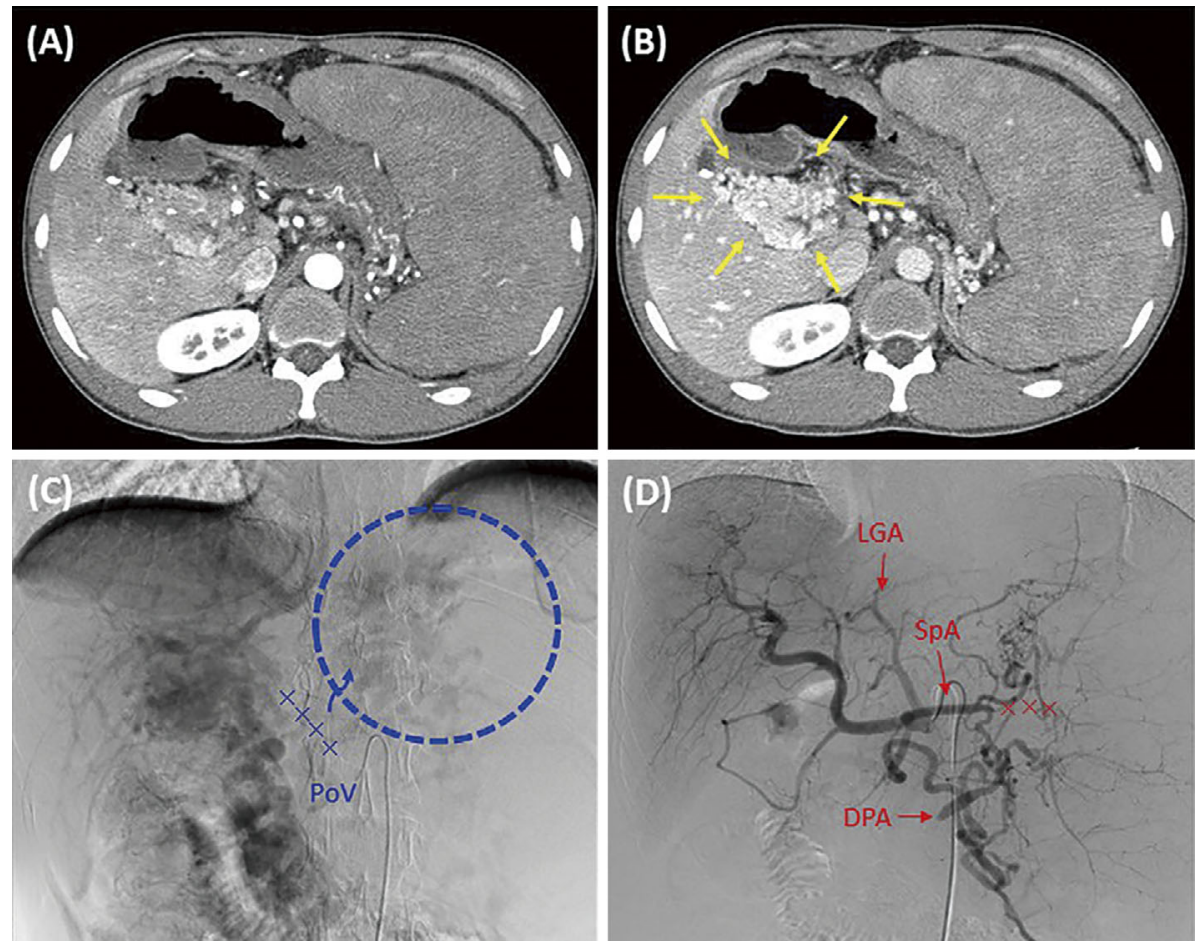

Figure 2. Images of abdominal computed tomography (CT) (A, B) and angiography (C, D). (A): Arterial phase, (B): Portal phase. The CT images showed massive splenomegaly and occlusion of the portal vein as well as marked hepatopetal collateral vessels (indicated by yellow arrows). (C) Image of superior mesenteric arteriography. Cavernous transformation was seen around the occluded portal vein and a collateral blood circulation was found around the esophagus and stomach. (D) Image of celiac arteriography (early phase). The main trunk of the splenic artery was occluded, and there was a collateral blood circulation originating from the dorsal pancreatic artery and left gastric artery.
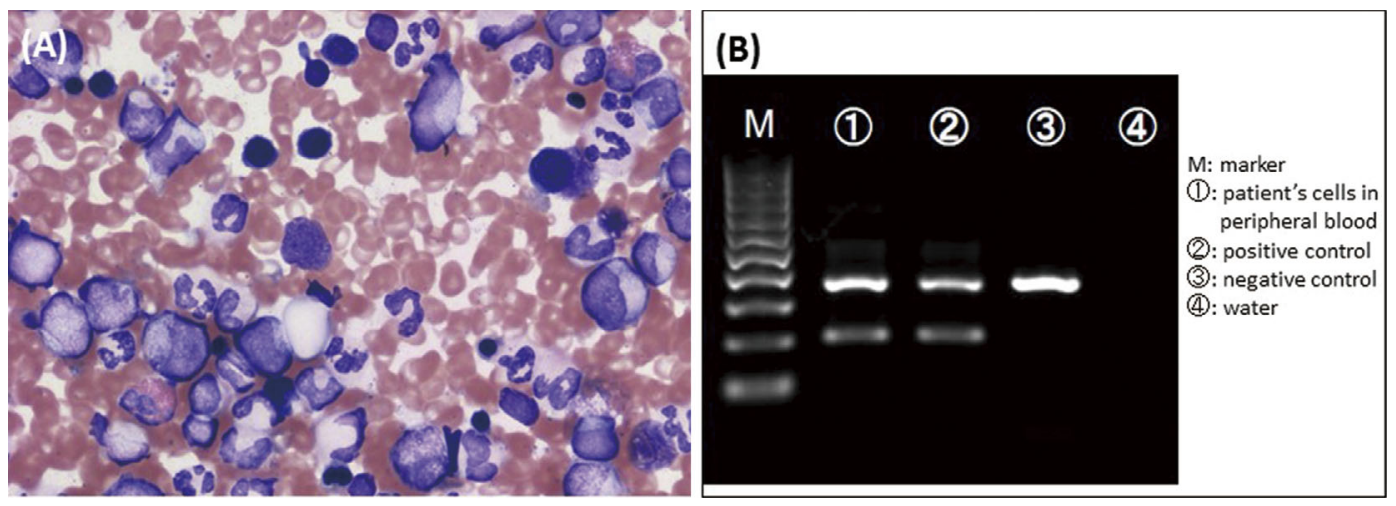

Figure 3. Diagnosis of polycythemia vera. The severe hypercellularity in the bone marrow (A) and positivity for the JAK2V617F mutation using allele-specific PCR (B) led to a diagnosis in this case of polycythemia vera. In the PCR analysis, the cell lines HEL and U937 were used as positive and negative controls, respectively.

row examination was not performed at that time because of the patient's economic constraints.

We followed the patient carefully, and, three months after the initial visit to our hospital, a blood examination showed a white blood cell count of $17,230 / \mu \mathrm{L}$, red blood cell count of $655 \times 10^{4} / \mu \mathrm{L}$ and platelet cell count of $365 \times 10^{3} / \mu \mathrm{L}$, indicating an increase in all three blood cell lines. Therefore, we again consulted the hematologist, and a gene mutation of JAK2V617F was detected (Fig. 3A). Bone marrow aspiration was also performed, which revealed severe hypercellularity, compatible with PV (Fig. 3B).

Finally, polycythemia vera was diagnosed based on these findings. The patient was treated with hydroxyurea to suppress myeloproliferative disease. The three blood cell lines gradually decreased, and the variceal condition has remained stable, with no new bleeding episodes thus far. 


\section{Discussion}

Non-cirrhotic portal vein thrombosis may be seen in patients with chronic myeloid leukemia (3), parasitoses such as schistosomiasis (4), deficiency of the natural anticoagulant proteins $\mathrm{C}, \mathrm{S}$ or antithrombin (5), hereditary thrombophilia related to mutations of prothrombin or factor $\mathrm{V}(6)$ and PV (1), as in the current case. Portal vein thrombosis in the acute phase is accompanied by clinical symptoms such as stomach aches, nausea, vomiting and/or fever. Symptoms related to portal hypertension, such as splenomegaly, anemia, leukopenia, thrombocytopenia and variceal bleeding, may be provoked in chronic cases (7). The current case involved esophageal variceal rupture associated with anemia and a normal platelet count as well as a slight increase in the white blood cell count. Therefore, it was difficult to reach a diagnosis of PV on the patient's first visit. Finally, we diagnosed PV after the disease-specific mutation JAK2V617F was detected.

The tyrosine kinase JAK2 plays an essential role in the signaling pathway of homodimeric receptors for cytokines, such as erythropoietin, thrombopoietin and granulocyte colony stimulating factor. The counts of all three blood cell lines may be increased via the JAK2V617F mutation, which causes the constitutive phosphorylation of STAT5 and subsequent cell transformation (8). It has been reported that the $J A K 2 V 617 F$ mutation is present in more than $90 \%$ of patients with PV (9-12). PV is a MPN characterized by a tendency to develop thrombohemorrhagic complications in addition to a life-long risk of transformation into myelofibrosis and, more rarely, acute leukemia (13-15). Recently, longterm follow-up studies have reported that the median survival of patients with $\mathrm{PV}$ after diagnosis is approximately 14 years, which is significantly worse than that of the age- and sex-matched healthy population $(16,17)$.

Typically, PV is suspected in patients exhibiting elevated hemoglobin or hematocrit levels; however, splenomegaly and/or portal venous thrombosis are also important symptoms for the diagnosis of PV. Portal hypertension reportedly occurs as a complication in 10-17\% of PV patients (18) and may be accompanied by esophagogastric variceal hemorrhage (19). In the present case, the patient was rather anemic on his first visit because of hemorrhaging, while the WBC and platelet counts were almost normal, although he had severe splenomegaly as well as both splenic and hepatic vein thrombosis. The severe splenomegaly might have caused the relatively low complete blood count. We performed JAK2V617F screening and obtained a positive result, which lead to the diagnosis of PV after acquiring confirmation based on an examination of the bone marrow. A recent meta-analysis reported that JAK2V617F screening in splanchnic vein thrombosis (SVT) patients without typical hematological MPN features identified MPN in $15.4 \%$ of the screened patients with portal vein thrombosis (PVT), suggesting that JAK2V617F screening should be considered for inclusion in the diagnostic workup of PVT patients (2).

The main goal of treatment for PV is to prevent the occurrence of thrombotic and bleeding complications (20). Traditionally, hydroxyurea has been used as the first-line treatment for patients with PV at high risk of vascular complications (21). Moreover, antiplatelet drugs, such as aspirin, are usually given at low doses to most patients with $\mathrm{PV}$ in order to prevent thrombosis (20). However, it must be kept in mind that treatment with aspirin should only be provided to those patients for whom the reduction of the risk of thrombosis outweighs the increased risk of bleeding associated with aspirin therapy and the platelet dysfunction commonly present in subjects with these diseases. In fact, the current patient was suspected to have platelet dysfunction because it took a few hours to stop the bleeding by applying pressure to the wound after bone marrow aspiration. Accordingly, we did not use aspirin in this case.

In the current case, we were unable to perform additional EISL to prevent rupture of the esophagogastric varices because this therapy might have worsened the portal thrombosis. Therefore, we should have considered other preventive treatments. Balloon-occluded transfemoral obliteration was considered; however, it was not indicated because the patient did not have a gastro-renal shunt. Percutaneous transhepatic obliteration and transjugular intrahepatic portalhepatic venous shunting were not indicated due to massive portal thrombosis. Patients with concomitant esophagogastric varices can reportedly be treated effectively with splenectomy $(19,22)$; however, it is evident that the absence of a spleen carries a risk of various infections and an increase in all three blood cell lines. Moreover, it must be considered that patients who undergo splenectomy have a risk of new thrombosis (23) requiring the use of antiplatelet drugs. As a result of the discussions with the hematologist and surgeons, we decided not to perform splenectomy and rather to start treatment with hydroxyurea, which suppresses hematogenesis. We have been following up the varices without treatment at three-month intervals, and the varices have not worsened.

In conclusion, we experienced the case of a male Filipino patient diagnosed with PV after the rupture of esophageal varices. MPNs, such as PV, should be suspected in cases featuring portal hypertension and/or thrombosis of unknown origin as well as splenomegaly without pancytopenia. In addition, JAK2V617F screening provides informative clues for the diagnosis of latent PV.

\section{The authors state that they have no Conflict of Interest (COI).}

\section{References}

1. Stuart BJ, Viera AJ. Polycythemia vera. Am Fam Physician 69: 2139-2144, 2004.

2. Smalberg JH, Arends LR, Valla DC, Kiladjian JJ, Janssen HL, Leebeek FW. Myeloproliferative neoplasms in budd-chiari syndrome and portal vein thrombosis: a meta-analysis. Blood 120: 
4921-4928, 2012.

3. Aksu T, Erdem AY, Fettah A, et al. Massive splenic infarction and portal vein thrombosis in children with chronic myeloid leukemia. J Pediatr Hematol Oncol 36: e471-e472, 2014.

4. Olveda DU, Olveda RM, Montes CJ, et al. Clinical management of advanced schistosomiasis: a case of portal vein thrombosisinduced splenomegaly requiring surgery. BMJ Case Rep 2014 piiibcr2014203897, 2014.

5. Fisher NC, Wilde JT, Roper J, Elias E. Deficiency of natural anticoagulant proteins $\mathrm{c}, \mathrm{s}$, and antithrombin in portal vein thrombosis: a secondary phenomenon? Gut 46: 534-539, 2000.

6. Qi X, Ren W, De Stefano V, Fan D. Associations of coagulation factor V Leiden and prothrombin G20210A mutations with BuddChiari syndrome and portal vein thrombosis: A systematic review and meta-analysis. Clin Gastroenterol Hepatol 12: 1801-12.e7, 2014

7. Webster GJ, Burroughs AK, Riordan SM. Review article: portal vein thrombosis: new insights into aetiology and management. Aliment Pharmacol Ther 21: 1-9, 2005.

8. Staerk J, Constantinescu SN. The jak-stat pathway and hematopoietic stem cells from the jak2 v617f perspective. Jak-Stat 1: 184-190, 2012.

9. Baxter EJ, Scott LM, Campbell PJ, et al. Acquired mutation of the tyrosine kinase jak2 in human myeloproliferative disorders. Lancet 365: 1054-1061, 2005.

10. James C, Ugo V, Le Couedic JP, et al. A unique clonal jak2 mutation leading to constitutive signalling causes polycythaemia vera. Nature 434: 1144-1148, 2005

11. Kralovics R, Passamonti F, Buser AS, et al. A gain-of-function mutation of jak2 in myeloproliferative disorders. N Engl J Med 352: 1779-1790, 2005.

12. Levine RL, Wadleigh M, Cools $\mathrm{J}$, et al. Activating mutation in the tyrosine kinase jak2 in polycythemia vera, essential thrombocythemia, and myeloid metaplasia with myelofibrosis. Cancer Cell 7: 387-397, 2005.

13. Polycythemia vera: The natural history of 1213 patients followed for 20 years. Gruppo Italiano Studio Policitemia. Ann Inter Med 123: 656-664, 1995.
14. Campbell PJ, Green AR. Management of polycythemia vera and essential thrombocythemia. Hematology/the Education Program of the American Society of Hematology American Society of Hematology Education Program. 2005: 201-208.

15. Wanless IR, Peterson P, Das A, Boitnott JK, Moore GW, Bernier $\mathrm{V}$. Hepatic vascular disease and portal hypertension in polycythemia vera and agnogenic myeloid metaplasia: a clinicopathological study of 145 patients examined at autopsy. Hepatology (Baltimore, Md) 12: 1166-1174, 1990 .

16. Tefferi A, Rumi E, Finazzi G, et al. Survival and prognosis among 1545 patients with contemporary polycythemia vera: an international study. Leukemia 27: 1874-1881, 2013.

17. Tefferi A, Guglielmelli P, Larson DR, et al. Long-term survival and blast transformation in molecularly annotated essential thrombocythemia, polycythemia vera, and myelofibrosis. Blood 124: 2507-2513; quiz 2615, 2014.

18. Ward HP, Block MH. The natural history of agnogenic myeloid metaplasia (amm) and a critical evaluation of its relationship with the myeloproliferative syndrome. Medicine 50: 357-420, 1971.

19. Sullivan A, Rheinlander H, Weintraub LR. Esophageal varices in agnogenic myeloid metaplasia: disappearance after splenectomy. A case report. Gastroenterology 66: 429-432, 1974.

20. Barbui T, Barosi G, Birgegard G, et al. Philadelphia-negative classical myeloproliferative neoplasms: critical concepts and management recommendations from european leukemianet. J Clin Oncol 29: 761-770, 2011.

21. Sever M, Newberry KJ, Verstovsek S. Therapeutic options for patients with polycythemia vera and essential thrombocythemia refractory/resistant to hydroxyurea. Leuk Lymphoma 55: 2685-2690, 2014.

22. Lukie BE, Card RT. Portal hypertension complicating myelofibrosis: reversal following splenectomy. Can Med Assoc J 117: 771772, 1977.

23. Cortelazzo S, Viero P, Finazzi G, D'Emilio A, Rodeghiero F, Barbui T. Incidence and risk factors for thrombotic complications in a historical cohort of 100 patients with essential thrombocythemia. J Clin Oncol 8: 556-562, 1990.

(C) 2015 The Japanese Society of Internal Medicine http://www.naika.or.jp/imonline/index.html 